\title{
Erratum to: Bias in protein and potassium intake collected with 24-h recalls (EPIC-Soft) is rather comparable across European populations
}

\author{
Sandra P. Crispim • Anouk Geelen • Jeanne H. M. de Vries · Heinz Freisling • Olga W. Souverein • \\ Paul J. M. Hulshof • Marga C. Ocke • Hendriek Boshuizen • Lene F. Andersen • Jiri Ruprich • Willem De Keyzer • \\ Inge Huybrechts • Lionel Lafay • Maria S. de Magistris • Fulvio Ricceri • Rosario Tumino • Vittorio Krogh • \\ H. Bas Bueno-de-Mesquita • Joline W. J. Beulens • Marie-Christine Boutron-Ruault • Androniki Naska • \\ Francesca L. Crowe $\cdot$ Heiner Boeing $\cdot$ Alison McTaggart $\cdot$ Rudolf Kaaks $\cdot$ Pieter van't Veer $\cdot$ Nadia Slimani
}

Published online: 11 January 2012

(C) Springer-Verlag 2012

\section{Erratum to: Eur J Nutr \\ DOI 10.1007/s00394-011-0279-z}

Unfortunately, one of the authors' names has been misspelled in the original publication of the article. The correct name should read De Keyzer W.

The online version of the original article can be found under doi:10.1007/s00394-011-0279-z.

S. P. Crispim - A. Geelen · J. H. M. de Vries ·

O. W. Souverein · P. J. M. Hulshof · H. Boshuizen ·

P. van't Veer

Division of Human Nutrition, Wageningen University,

Wageningen, The Netherlands

S. P. Crispim $(\bowtie) \cdot$ H. Freisling · I. Huybrechts · N. Slimani Dietary Exposure Assessment Group, International Agency for Research on Cancer (IARC), 150, cours Albert Thomas, 69372 Lyon Cedex 08, France

e-mail: sandracrispim@gmail.com

M. C. Ocke - H. Boshuizen - H. B. Bueno-de-Mesquita National Institute for Public Health and the Environment (RIVM), Bilthoven, The Netherlands

L. F. Andersen

Department of Nutrition, Institute of Basic Medical Sciences, University of Oslo, Oslo, Norway

J. Ruprich

Department for Food Safety and Nutrition,

National Institute of Public Health, Brno, Czech Republic

W. De Keyzer

Department of Nutrition and Dietetics,

University College Ghent, Ghent, Belgium

W. De Keyzer · I. Huybrechts

Department Public Health, Ghent University, Ghent, Belgium
The complete author group is provided below:

Sandra P. Crispim · Anouk Geelen · Jeanne H. M. de Vries . Heinz Freisling · Olga W. Souverein · Paul J. M. Hulshof · Marga C. Ocke - Hendriek Boshuizen - Lene F. Andersen . Jiri Ruprich · Willem De Keyzer · Inge Huybrechts ·

L. Lafay

French Agency for Food, Environmental and Occupational Health Safety (ANSES), Paris, France

M. S. de Magistris

Department of Public Clinical and Experimental Medicine,

Federico II, Naples, Italy

F. Ricceri

Human Genetics Foundation (HUGEF), Turin, Italy

R. Tumino

Cancer Registry and Histopathology Unit, "Civile M.P.Arezzo"

Hospital, Ragusa, Italy

V. Krogh

Nutritional Epidemiology Unit, Fondazione IRCCS Istituto

Nazionale Tumori, Milan, Italy

H. B. Bueno-de-Mesquita

Department of Gastroenterology and Hepatology,

University Medical Centre Utrecht, Utrecht, The Netherlands

J. W. J. Beulens

Julius Center for Health Sciences and Primary Care,

University Medical Center Utrecht, Utrecht, The Netherlands

M.-C. Boutron-Ruault

Inserm, Centre for Research in Epidemiology and Population

Health, Villejuif, France 
Lionel Lafay - Maria S. de Magistris · Fulvio Ricceri . Rosario Tumino · Vittorio Krogh · H. Bas Bueno-deMesquita · Joline W. J. Beulens · Marie-Christine Boutron-
Ruault · Androniki Naska · Francesca L. Crowe - Heiner Boeing · Alison McTaggart - Rudolf Kaaks · Pieter van't Veer · Nadia Slimani.

\section{A. Naska}

Department of Hygiene, Epidemiology and Medical Statistics,

WHO Collaborating Center for Food and Nutrition Policies,

University of Athens Medical School, Athens, Greece

F. L. Crowe

Nuffield Department of Clinical Medicine, Cancer Epidemiology

Unit, University of Oxford, Oxford, UK

H. Boeing

Department of Epidemiology, German Institute of Human

Nutrition, Potsdam, Rehbrücke, Germany

\section{A. McTaggart}

Department of Public Health and Primary Care,

University of Cambridge, Cambridge, UK

R. Kaaks

Division of Cancer Epidemiology,

German Cancer Research Center, Heidelberg, Germany 